\title{
Genistein and Daidzein effects on the physiological indices of Soybean Cyst Nematodes
}

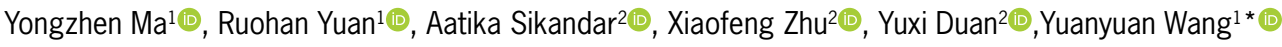

${ }^{1}$ Shenyang Agricultural University/College of Biosciences and Biotechnology, 120 Dongling Road -110866 - Shenhe District, Shenyang - China.

${ }^{2}$ Shenyang Agricultural University - Shenhe District, Shenyang - China.

*Corresponding author <wyuanyuan1225@syau.edu.cn>

Edited by: Paulo Cesar Sentelhas

Received July 16, 2020

Accepted November 05, 2020
ABSTRACT: Soybean cyst nematode (SCN, Heterodera glycines) is a chief plant-parasitic nematode of soybean. Application of synthetic chemical nematicides poses negative side effects to human health and the environment. Therefore, the search for a safe and effective approach is more relevant. This study evaluated the effects of Genistein and Daidzein on the physiological index of soybean cyst nematodes, individual morphology, reversal frequency, respiration, and body fluid leaking of second-stage juveniles (J2s) of soybean cyst nematode. The results showed that body length of $\mathrm{J} 2 \mathrm{~s}$ decreased, while stylet and tail transparent area elongated. Additionally, after the treatment, the body became hollow and shrunken, the J2s stiffened, whereas the reversal frequency decreased dramatically after $24 \mathrm{~h}$ of treatment. Moreover, the body fluid leakage was intensified and respiration was inhibited. Oxygen consumption decreased by $86.7 \%$ and $70.1 \%$, while, in contrast, electrical conductivity increased by $40.1 \%$ and $36 \%$ at $100 \mu \mathrm{g}$ $\mathrm{mL}^{-1}$ of Genistein and Daidzein, respectively, after $48 \mathrm{~h}$ of exposure. The smaller number of J2s in soybean roots, the slower development rate, and the abnormal sexual differentiation were found in greenhouse assay. Thus, Genistein and Daidzein, especially Genistein, have strong effects on the physiological index of soybean cyst nematodes. Moreover, the effects were time and dosage-dependent.

Keywords: Heterodera glycines, nematicides, respiration, morphology

\section{Introduction}

Nematoda is the phylum of Kingdom Animalia that can be found in almost any type of environment (Blaxter and Denver, 2012). With long-term evolution, nematodes have developed specialized morphological features, cuticles, muscles, nervous and digestive systems suitable for the habitats and feeding habits. An example is the mouthpart of plant parasite nematode, a needle-like stylet, which is used to puncture cells during feeding (Yeates et al., 1993). Stylet activity is a necessary part for invasion of and migration through roots (Bell et al., 2019). Stylet activity can be affected by chemical or biofactors, such as exposure to root exudate, and is known to stimulate stylet thrusting in some plant-parasitic nematodes (Warnock et al., 2016).

Soybean cyst nematode (SCN, Heterodera glycines) is one of the most devastating diseases in soybean crops worldwide. Soybean yield loss due to $H$. glycines has been estimated to amount more than US $\$ 1.5$ billion worldwide (Hosseini and Matthews, 2014). Once SCN penetrates and feeds inside the root tissue, juveniles sedentary endoparasites remain in a permanent feeding site inside the root for their remaining life (Yeates et al., 1993). The only state that infects soybean roots of SCN is J2. Subsequently, nematodes develop into males or females throughout three molts (J3, J4, and adults). Therefore, chemicals that affect the activity of $\mathrm{J} 2$, poisoned them, reduce J2 infestation ability, or even kill them, inhibiting their infection to plant roots and reducing the damage of SCN to soybean.

Secondary metabolites have high antioxidants and nematicidal ability and they cause deterioration to internal tissues and cuticle of nematodes (Lai et al., 2014). Other studies have demonstrated that isoflavone has a repelling effect on Caenorhabditis elegans and Bursaphelenchus xylophilus, affecting their movement and hatching (Lee et al., 2008; Zhao et al., 2007). Evidence shows that isoflavonoids impede SCN replication by influencing the sex ratio and the number of female eggs (Chin et al., 2018). Although studies have shown that exogenous isoflavones have the positive suppression ability on SCN J2s (Guo et al., 2017), their specific mode of action on SCN J2s is still unclear. Therefore, this study assessed the effects of Genistein and Daidzein on the morphology, oxygen consumption, body fluid infiltration, and reversal frequency of SCN J2s to better understand the physiological effects of Genistein and Daidzein on nematodes.

\section{Materials and Methods}

\section{Nematode collection method}

SCN race 3 was used in this study. Cysts were obtained from the experimental field in Shenyang, Liaoning, China $\left(41^{\circ} 50^{\prime} 4^{\prime \prime} \mathrm{N}, 116^{\circ} 19^{\prime} 53^{\prime \prime} \mathrm{E}\right.$, altitude $\left.70 \mathrm{~m}\right)$ and collected by following elutriation and hand-picking under a stereomicroscope. Cysts were surface-sterilized by immersion in $0.1 \% \mathrm{HgCl}_{2}$ solution for 1 min followed by rinsing three times with sterile distilled water. The cysts were then placed in Baermann funnel at $25^{\circ} \mathrm{C}$. Secondstage juveniles were collected from the bottom of the Baermann funnel every two or three days (Liu, 1995).

\section{Preparation of Genistein and Daidzein solution}

Genistein and Daidzein purchased from Merck KGaA, Darmstadt, Germany, were dissolved to $10 \mu \mathrm{g} \mathrm{mL}^{-1}, 50$ 
$\mu \mathrm{g} \mathrm{mL}-1$, and $100 \mu \mathrm{g} \mathrm{mL} \mathrm{m}^{-1}$ concentrations in dimethyl sulfoxide (DMSO, final volume less than $1 \%$ ), respectively, and frozen in aliquots until ready for use.

\section{Individual morphological assay}

SCN J2s were treated with different concentrations of Genistein and Daidzein under room temperature for $24 \mathrm{~h}$, and then body length, stylet, and tail transparent area of J2s were measured under the microscope. Sterile water with a small amount of DMSO (final volume of less than $1 \%$ ) was used as the control. Three independent experiments were conducted and each experiment included three replications.

\section{Reversal frequency assay}

Fresh and active SCN J2s were placed in a Petri dish filled with $1 \mathrm{~mL}$ Genistein and Daidzein. The movement behavior was measured according to the method of Tsalik with some modifications (Tsalik and Hobert, 2003). All assay dishes were pre-equilibrated to the room temperature. The reversal frequency $(\mathrm{RF})$ of J2s was measured at $1,3,6,12$, and $24 \mathrm{~h}$, with $1 \mathrm{~min}$ for each hour under stereomicroscope. Any changes from forward to the backward movement were scored as a reversal. Three replicates were set for each treatment and the nematodes treated with sterile water with a small amount of DMSO were used as the control.

\section{Respiration (oxygen consumption) assay}

Respiration of SCN J2s was measured by the oxygen electrode method to determine the effect of isoflavone on respiration of SCN J2s (Kohra et al., 2002; Qi et al., 2008). Approximately 20,000 SCN J2s were added into the solution that contained 10,50 , or $100 \mu \mathrm{g} \mathrm{mL}^{-1}$ of Genistein or Daidzein, respectively. Nematode suspension with a small amount of DMSO was used as the control. Oxygen consumption of J2s was measured by JPSJ-605 dissolved oxygen meter at $1,3,6,12,24$, and $48 \mathrm{~h}$ in each treatment group. Three replicates were set for each treatment. The test was conducted in a water bath at $25^{\circ} \mathrm{C}$. The control solution in the formula was the isoflavone solution with corresponding concentration and sterile water.

O.C of SCN J2s = oxygen in control solution - oxygen in SCN J2s suspension

where: O.C. is Oxygen Consumption of $S C N\left(\mathrm{mg} \mathrm{L}^{-1}\right)$.

\section{Body fluid infiltration assay}

Fluid leakage of J2s was studied by the electrical conductivity method (Kohno et al., 1981). Approximately 20,000 SCN J2s were added into the solution that contained 10,50 or $100 \mu \mathrm{g} \mathrm{mL} \mathrm{m}^{-1}$ of Genistein or Daidzein, respectively. Nematode suspension with a small amount of DMSO was used as the control. DdSJ-308a conductivity meter was used to determine the conductivity of SCN J2s at $1,3,6,12,24$, and $48 \mathrm{~h}$ in each treatment group. Three replicates were set for each treatment. In the formula, the control solution comprises an isoflavone solution and sterile water with corresponding concentration.

E.C of SCN J2s = E.C. of SCN J2s suspension - E.C. control solution

where: E.C. is Electric Conductivity of $\operatorname{SCN}\left(\mu \mathrm{S} \mathrm{cm}^{-1}\right)$.

\section{Greenhouse experiment (Infectivity and development assay)}

The experiment was carried out in a greenhouse of Shenyang Agricultural University, China $\left(41^{\circ} 49^{\prime} 33^{\prime \prime} \mathrm{N}\right.$, $134^{\circ} 34^{\prime} 9^{\prime \prime} \mathrm{E}$, at $72 \mathrm{~m}$ a.s.1.). The Liaodou15 soybean cultivars susceptible to SCN were used. The seeds were surface-sterilized with $0.5 \% \mathrm{NaClO}$ for $10 \mathrm{~min}$ and washed several times with sterile distilled water, airdried, and then germinated on filter paper in distilled water in Petri dishes and incubated at $28 \pm 1{ }^{\circ} \mathrm{C}$ for one week. The seeds were sown in $18-\mathrm{cm}$ plastic pots that contained a sterile soil mixture (topsoil: sand: vermiculite, $3: 2: 1$ ). The seedlings were inoculated with 2,000 living J2s treated with different concentrations of Genistein and Daidzein at the cotyledon stage for $24 \mathrm{~h}$. J2s treated with sterilized water were used in the control. Three days after inoculation, soybean seedlings were transferred to new plastic containers filled with sterile soil mixture and irrigated with 1/4 Hoagland nutrient solution in a growth chamber under normal conditions $\left(25 / 20{ }^{\circ} \mathrm{C}\right.$ day/night temperature, relative humidity $60-80$, and $16 \mathrm{~h}$ light period/day at the intensity of $160 \mu \mathrm{mol}$ photons $\mathrm{m}^{-2} \mathrm{~s}^{-1}$ ). The development rate was observed accurately. To avoid further penetration of $\mathrm{J} 2 \mathrm{~s}$, seedlings were moved to new containers. The number of females of J2s, J3s, and J4s inside the roots at $7 \mathrm{dpi}, 14 \mathrm{dpi}, 21 \mathrm{dpi}$, and $28 \mathrm{dpi}$ were observed and counted using a stereomicroscope after the roots were stained with acid fuchsin (Hussey, 1985; Sikandar et al., 2019). The experiment was repeated three times.

\section{Statistical Analysis}

The SPSS17.0 software was used to analyze the significance of the difference under the conditions of the Duncan's multiple range test $p<0.05$ and Graphpad Prism v.8.0. were used to analyzed the experimental data and draw the charts.

\section{Results}

\section{Individual morphology assay}

Both Genistein and Daidzein affected the body length, stylet, and tail translucency of SCN J2s. Genistein had 
a more pronounced effect on SCN J2s compared to Daidzein, and this effect deepened with an increase in the concentration of isoflavone. The body length of SCN J2s was treated with $100 \mu \mathrm{g} \mathrm{mL} \mathrm{m}^{-1}$ and $50 \mu \mathrm{g}$ $\mathrm{mL}^{-1}$. Genistein was greatly reduced, followed by $100 \mu \mathrm{g} \mathrm{mL}^{-1}$ Daidzein-treated nematodes. In terms of stylets and tail translucent region, with the exception of $10 \mu \mathrm{g} \mathrm{mL} \mathrm{mL}^{-1}$ Daidzein, the other treatment was considerably higher. The influence of Genistein on the stylet and the transparent tail area was slightly higher than that of Daidzein at the corresponding concentration (Table 1).

\section{Reversal frequency assay}

Nematodes displayed a non-directional thrashing behavior in all treatments; however, the reversal

Table 1 - Treatment effect on the morphology of Soybean Cyst Nematode

\begin{tabular}{|c|c|c|c|}
\hline Treat. & Body length & Stylet & Tail's transparent \\
\hline & & & \\
\hline $10 \mu$ & $b^{b}$ & $43.39 \pm 0.11^{\mathrm{d}}$ & \\
\hline $50 \mu$ & $715.55=$ & $43.74 \pm 0.11^{c}$ & 48.3 \\
\hline D100 & $4^{d}$ & $44.10 \pm$ & $36^{c}$ \\
\hline G10 $\mu \xi$ & 716.3 & $44.08 \pm 0.07^{b c}$ & $.09^{b}$ \\
\hline $\mathrm{G} 50 \mu \mathrm{g}$ & 699.35 & $44.55 \pm 0.47^{a}$ & $.32^{\mathrm{a}}$ \\
\hline G100 $\mu \mathrm{g} \mathrm{mL}$ & $697.53 \pm 0.94 \mathrm{e}$ & $44.74 \pm 0.05^{a}$ & $51.98 \pm 0.12^{\mathrm{a}}$ \\
\hline Control & $725.13 \pm 2.31^{a}$ & $43.26 \pm 0.15^{d}$ & $46.70 \pm 0.09^{d}$ \\
\hline
\end{tabular}

Data presents the mean \pm standard deviation. The same letters in columns are significantly similar according to the Duncan's multiple range test ( $p>$ 0.05). frequency of SCN J2s slowed down to a certain extent in both isoflavones treatments. The reversal frequency of SCN J2s decreased correspondingly with the increasing time and isoflavone concentration. Genistein, at 100 and 50 ug $\mathrm{mL}^{-1}$ concentrations, imposed a greater effect on the reversal frequency. The nematodes swung much slower in Genistein than in Daidzein at $12 \mathrm{~h}$ after treatment and most nematodes were in a rigid state

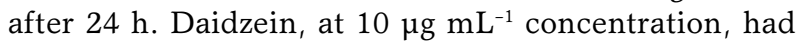
little effect on the nematode swing frequency in the early stage and even promoted its swing phenomenon after treatment for $1 \mathrm{~h}$. Daidzein had a relatively large effect on the swing frequency at a concentration of $100 \mu \mathrm{g} \mathrm{mL} \mathrm{mL}^{-1}$ after treated $24 \mathrm{~h}$. Some nematodes waved slowly, even basically lost their ability to move or died (Figure 1).

\section{Respiration (oxygen consumption) assay}

Genistein affected the respiration of SCN J2s. Compared with the control, oxygen consumption of nematodes treated by Genistein was significantly reduced after $6 \mathrm{~h}$ of treatment. Oxygen consumption of nematode treated by Genistein at $100 \mu \mathrm{g} \mathrm{mL} \mathrm{m}^{-1}$ and $50 \mu \mathrm{g} \mathrm{mL} \mathrm{m}^{-1}$ showed a sharp decrease and almost stopped after $48 \mathrm{~h}$. The effect of $100 \mu \mathrm{g} \mathrm{mL} \mathrm{m}^{-1}$ Daidzein was similar to that of $100 \mu \mathrm{g} \mathrm{mL} \mathrm{m}^{-1}$ Genistein. Oxygen consumption in 12-48 $\mathrm{h}$ decreased linearly and gradually approached $100 \mu \mathrm{g}$ $\mathrm{mL}^{-1}$ Genistein. After $12 \mathrm{~h}$ of treatment with $100 \mu \mathrm{g}$ $\mathrm{mL}^{-1}$ and $50 \mu \mathrm{g} \mathrm{mL}^{-1}$ Daidzein, the decrease of nematode oxygen consumption slowed down and tended to be flat, which was significantly different from other treatments (Figure 2).

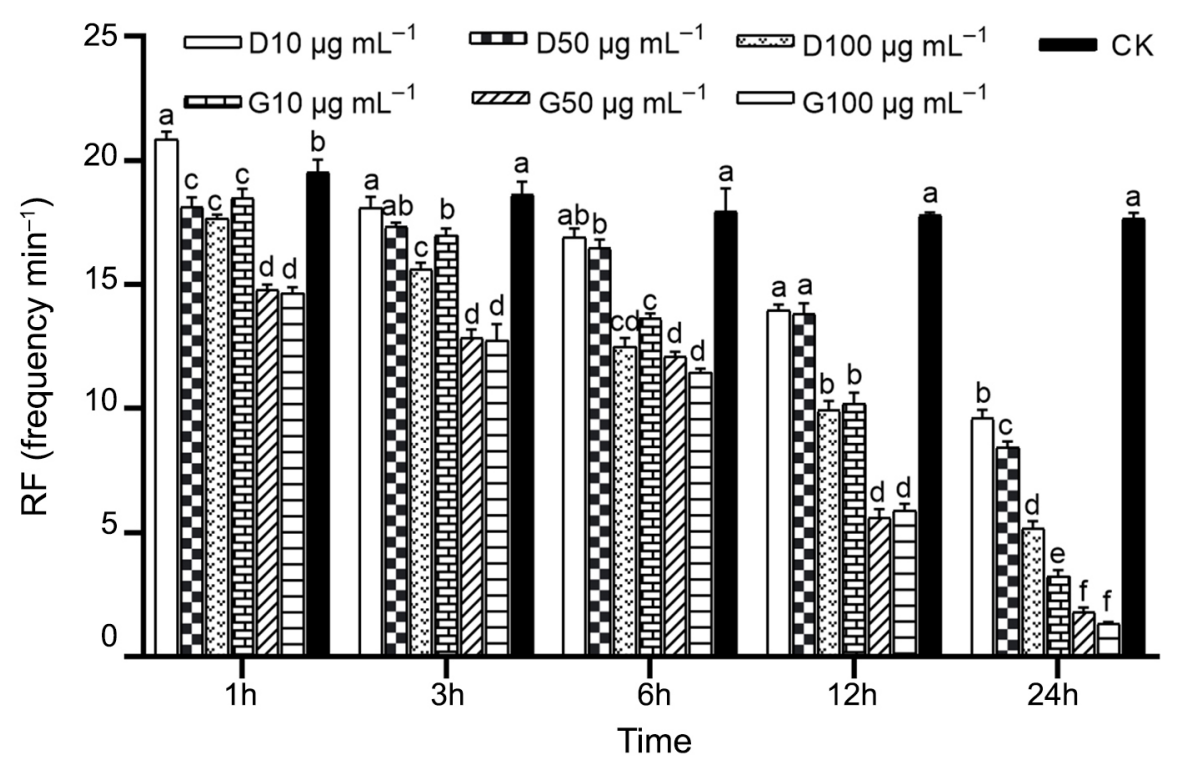

Figure 1 - Reversal frequency of nematodes during Genistein and Daidzein treatments. The error bars illustrated the mean \pm standard error. Different letters on the bar indicate that values are significantly different according to the Duncan's multiple range test at $p>0.05$. 


\section{Body fluid infiltration assay}

In the treatment of $\mathrm{SCN} \mathrm{J2s} \mathrm{with} \mathrm{two} \mathrm{isoflavones}$ at different concentrations, the conductivity of the nematode suspension increased steadily in the early stage of SCN J2s suspension treated with $50 \mu \mathrm{g} \mathrm{mL}^{-1}$, $100 \mu \mathrm{g} \mathrm{mL} \mathrm{m}^{-1}$, and $100 \mu \mathrm{g} \mathrm{mL} \mathrm{m}^{-1}$. The Daidzein solution rapidly increased after $6 \mathrm{~h}$, while the conductivity of nematode suspension treated with $10 \mu \mathrm{g} \mathrm{mL} \mathrm{m}^{-1}$ Genistein gradually stabilized. Similarly, except for conductivity at $100 \mu \mathrm{g} \mathrm{mL} \mathrm{m}^{-1}$ when the Daidzein treatment was higher than that of conductivity Genistein $10 \mu \mathrm{g} \mathrm{mL} \mathrm{L}^{-1}$ after $24 \mathrm{~h}$, Genistein had a greater effect on nematode suspension (Figure 3).

\section{Infectivity and development assay}

Given that two isoflavones treatments affect the body length, respiration, and other physiological indexes of $\mathrm{J} 2$, we decided to inoculate the treated J2s to determine whether Genistein and Daidzein treatments affected the infectivity and development of J2.

The results showed that the total number of nematodes in each treatment was significantly smaller than that of control. The number of J2s in each treatment group was significantly smaller than that of the control group at $7 \mathrm{dpi}$. As the treatment concentration increased, the number of J2s that invaded soybean root successfully was significantly reduced; however, it was

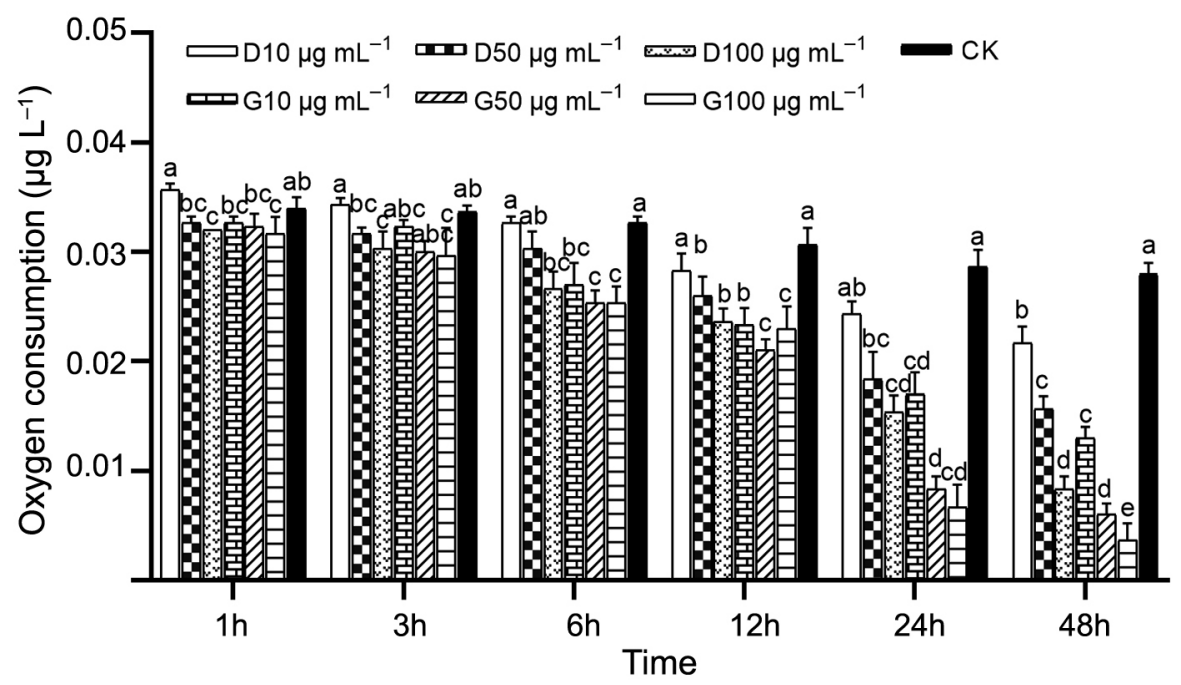

Figure 2 - Respiration of nematodes during Genistein and Daidzein treatments. The error bars illustrated the mean \pm standard error. Different letters on the bar indicate that values are significantly different according to the Duncan's multiple range test at $p>0.05$.

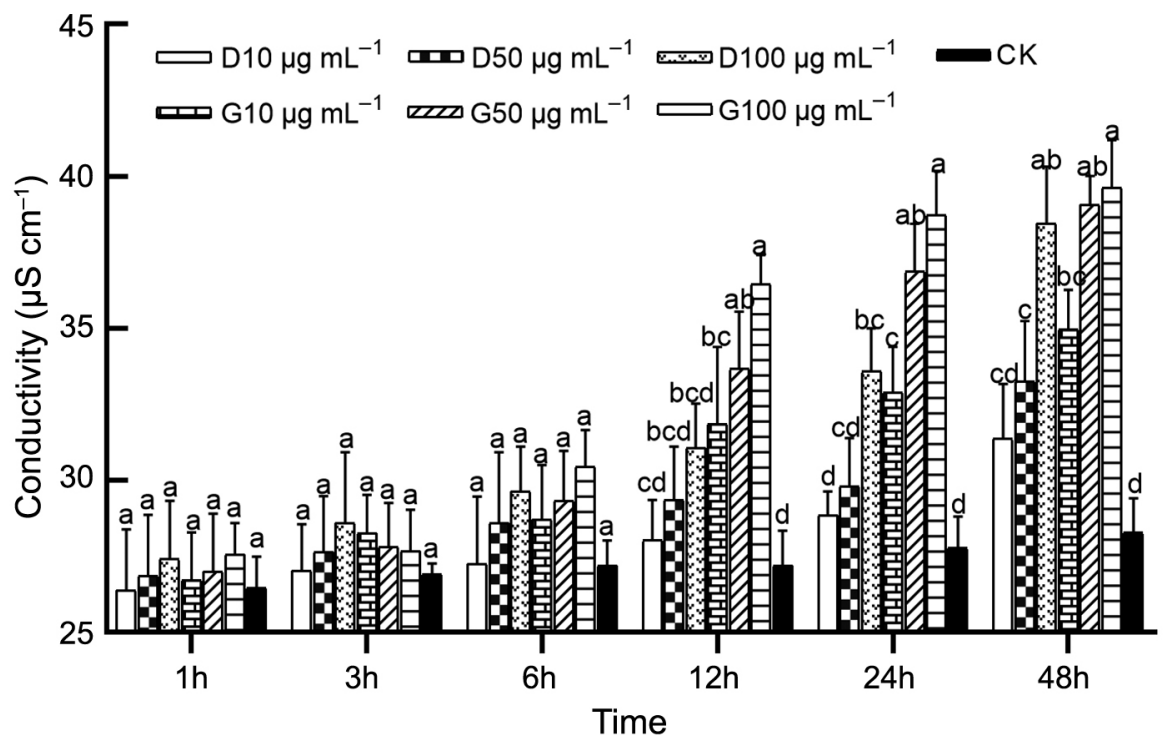

Figure 3 - Body fluid leaking during Genistein and Daidzein treatments. The error bars illustrated the mean \pm standard error. Different letters on the bar indicate that values are significantly different according to the Duncan's multiple range test at $p>0.05$. 

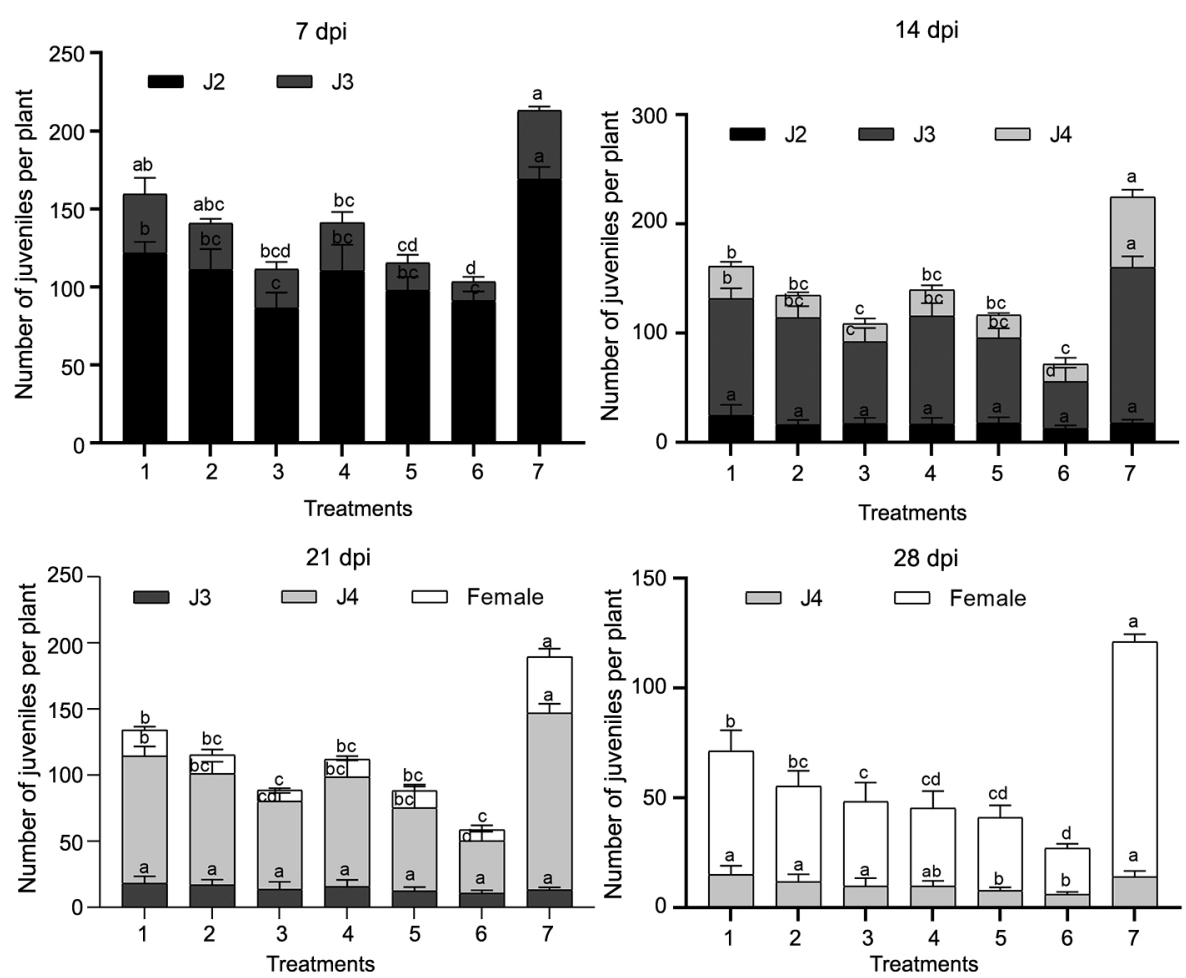

Figure 4 - The number of Soybean Cyst Nematodes in soybean roots at different development stages after $7 \mathrm{dpi}, 14 \mathrm{dpi}, 21 \mathrm{dpi}, 28 \mathrm{dpi}$ inoculated with live J2s treated for $24 \mathrm{~h}$ with Genistein and Daidzein. The error bars illustrated the mean \pm standard error. Different letters on the bar indicate that values are significantly different according to the Duncan's multiple range test at $p>0.05\left(1=\mathrm{D} 10 \mu \mathrm{g} \mathrm{mL} \mathrm{m}^{-1}, 2=\mathrm{D} 50 \mu \mathrm{g}\right.$ $\left.\mathrm{mL}^{-1}, 3=\mathrm{D} 100 \mu \mathrm{g} \mathrm{mL}-1,4=\mathrm{G} 10 \mu \mathrm{g} \mathrm{mL}-1,5=\mathrm{G} 50 \mu \mathrm{g} \mathrm{mL}-1,6=\mathrm{G} 100 \mathrm{D} 50 \mu \mathrm{g} \mathrm{mL} \mathrm{m}^{-1}, 7=\mathrm{CK}\right)$.

not significantly different at the same concentration of Genistein and Daidzein. Most J2s developed into J3 at 14 dpi. At this time, the number of $\mathrm{J} 2 \mathrm{~s}$ in control was not significantly different from that in other treatments, indicating that the treatments delayed the development of J2s. J4 was the dominant state at 21 dpi. Data showed that the total number of nematodes in each treatment especially in G100 $\mu \mathrm{g} \mathrm{mL} \mathrm{mL}^{-1}$ treatment decreased significantly, which means that J2 that successfully invaded the roots did not colonize and develop further. At $28 \mathrm{dpi}$, J4 developed into adults. Further comparison of the number of females found that isoflavone-treated J2s could affect sex differentiation during nematode development (Figures 4 and 5).

\section{Discussion}

Admittedly, all plant-parasitic nematodes must be able to locate and feed on their host to survive. They feed on cell soluble drilled through a stylet, a thin, long, hollow, needle-like structure (Grundler et al., 1991). The nematode uses this stylet supported by muscles to puncture plant cells to secrete protein and enzyme that aids the nematode to digest plant cell wall and withdraw the cell content, such as sugar (Fanelli et al., 2014; Vieira et al., 2015), enabling plant invasion and

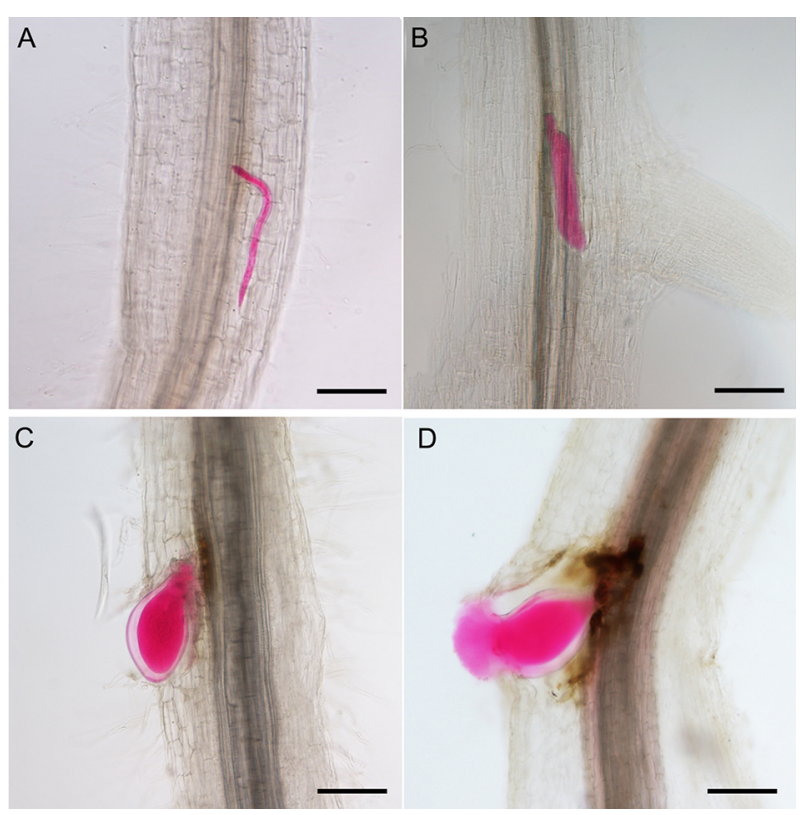

Figure 5 - Development of $\mathrm{SCN}$ in soybean roots $\mathrm{Bar}=200 \mu \mathrm{m})$. (A) $\mathrm{J} 2$ in the root system; (B) J3 in the root system; (C) J4 (o) in the root system; (D) Female in the root system. (Photograph Credit: Yuanyuan Wang). 
parasitism (Lambert and Bekal, 2002). The stylet is connected to the pharynx that, in turn, is connected to the intestine. The muscles are attached to the nematode hypodermis and surrounded the pharynx (Basyoni and Rizk, 2016), which is used to control the extension and contraction of the stylet to eject secretions from its salivary glands into and around plant cells and pump food into its intestine. Some authors reported that helminth parasite exposed to genistein caused flaccid paralysis in them and subsequent death of the parasites (Tandon and Lyndem, 2010; Toner et al., 2009), Terpenoids produce a rapid paralysis of worms and inhibit egg hatching (Hernando et al., 2019). Genistein-treated helminth parasites exhibited changes in alterations and deformity in their tegmental architecture (Kar and Tandon, 2000; Pal and Tandon, 1998). In our study, the Genistein and Daidzein treatment greatly affected the morphology of J2s. The body length of J2s shortened, while the stylet and tail transparent area elongated. The results indicated that Genistein and Daidzein cause paralysis or slack the muscles surrounding the pharynx, even the muscles of the whole body. Further, muscle paralysis or slack affected not only nematode movement and penetration, but also its feeding or withdrawal of nutrition. Many works have been carried out to clarify that nutrition is essential for nematode development and sex differentiation. Cyst nematodes are sexually dimorphic. Female cyst nematodes require, on average, 29 times more food compared with males (Muller et al., 1981). The male or female differentiation depends on host factors, such as the intensity of the host immune responses and availability of nutrients. Under favorable conditions with plenty of nutrients, more females are developed, whereas mainly male nematodes develop under nutrient deficiency (Anjam et al., 2020).

Nematodes are motile animals; nevertheless, most can move no more than a meter through the soil within their lifetime. Nematodes crawl by a wave of muscle contraction along the body in the dorsoventral plane, waves traveling from head to tail result in the forward movement. Reversals have long been recognized as a basic component of nematode locomotory behavior (Croll, 1975). A reversal frequency, previously termed an "omega turn" (Croll, 1975; Pierce-Shimomura et al., 1999), means that each animal can change from forward to backward movement within $3 \mathrm{~min}$. Tsalik and Hobert (2003) demonstrated that nematode significantly decreased their reversal frequency under weakness or exhaustion due to lack of food and allowed straight movement away from unfavorable conditions. Nervous systems in nematodes vary in their complexity. Locomotory, egg-laying, defecation, feeding, intestines, and pharyngeal muscles are controlled by a small number of specialized motor neurons (Schafer, 2016). The muscles are attached longitudinally to the nematode hypodermis, allowing them to move only in a sinusoidal (snake-like) motion. Isoflavones are capable of inducing quiescence through slowing the movement of juveniles of plant-parasitic nematodes and repelling them by changing their migration towards the roots (Chin et al., 2018). Previous studies have also demonstrated that isoflavone inhibited or slowed the motility of Heterodera zeae, Meloidogyne javanica and Meloidogyne incognita juveniles (Faizi et al., 2011; Shaukat et al., 2003; Sommerville and Davey, 2002; Wuyts et al., 2006). Genistein and terpenoids have shown to cause paralysis and alterations in the tegument and tegumental enzymes of nematodes (Tandon and Das, 2018). Exposure to $0.5 \mathrm{mg} \mathrm{mL}^{-1}$ Genistein provided a pronounced reduction of the activity of non-specific esterases (NSE) and cholinesterase (ChE), which were found in close association with the central and peripheral nervous components (Maule et al., 1993). The activity of acetylcholinesterase (AChE), the specific $\mathrm{ChE}$ in the parasite, points towards acetylcholine, an inhibitory neurotransmitter (Pal and Tandon, 1998). The reversal rate declined significantly after $24 \mathrm{~h}$ of treatment and the effects of treatment with Genistein and Daidzein ultimately resulted in muscle paralysis and damage to the nervous system of nematodes. Nematodes lack defined respiratory or circulatory systems (Basyoni and Rizk, 2016). Diffusion of water, gasses, and metabolites were depended on their semi-permeable body walls and internal transport. Oxygen consumption of nematodes is 50 times more than that of humans (Duan et al., 2011). Recent evidence underlines mitochondrial function as a potential contributor to the maintenance of organismal homeostasis and viability (Vafai and Mootha, 2012). The rate of oxygen consumption is a vital marker indicating cellular function under normal or metabolically challenged conditions, including a fundamental indicator of mitochondrial function, reflecting on reactive oxygen species (ROS) production and metabolic activity during lifetime under normal or metabolically challenged conditions. Preez developed a novel method to measure the oxygen consumption rate of $C$. elegans and showed that the oxygen consumption rate is used as a promising functional measurement of toxicity (Preez et al., 2020). Respiration of C. elegans has also been used, although infrequently, to study the effect of toxicant exposure (Schouest et al., 2009). Isoflavones alter the mitochondrial respiration, as a result oxygen consumption of $M$. javanica, which is reduced and plays a vital role in the resistance of nematodes (Cesco et al., 2012). Our results also revealed that respiration inhibition was directly related to the Genistein and Daidzein concentration and exposure time. Coincidentally, the damage of cuticle in the body fluid infiltration assay also decreased the respiration rate of nematodes.

All nematodes have an external structure known as the cuticle, which is crucial for their development and survival (Page et al., 2014). The muscle layer and the cuticle enclose a fluid-like cavity, which is filled with fluid and hemolymph that appears as a clear, 
pink, almost cell-free solution that provides pressure against the cuticle to keep body shape, allowing movement (Basyoni and Rizk, 2016). Previous studies have reported that secondary metabolites or proteases from nematophagous bacteria and fungi, such as Bacillus spp., Hirsutella rhossiliensis, Paecilomyces lilocinas and Pezizomycotina spp. showed strong nematicidal potential and caused degradation to internal tissues and cuticle of nematodes (Lai et al., 2014; Son et al., 2007). Damaged cuticle decreased nematode motility and loss of activity led to nematode death. Cuticle damage occurred together with leakage of the inner materials of the nematode (Luo et al., 2007). The potential of a body or substance to conduct electrical current derives from particles that are positively and negatively charged and its travel inside the substance, resulting in electrical conductance (Jones, 2005). The more free ions present, the higher the conductivity. In our study, both Genistein and Daidzein increased the electrical conductivity of J2s and showed maximum body fluid leaking of $H$. glycine in the early stage of suspension treated. We found that the electrical conductivity is time and dosage-dependent. The outcomes of our study clearly demonstrated that the use of Genistein and Daidzein damaged the cuticle of nematode and caused the leakage of inner materials of the nematodes, compromising the nematode ability to keep the pressure of the whole body, normal body shape, and length.

Due to the restructuring of the body, elongated stylet, and paralysis, respiration reduced, the cuticle was damaged, and then it caused some difficulties for the nematode to travel, locate, and penetrate the host, and remove the nutrient from the soybean root. Consequently, a slower rate of development, abnormal sexual differentiation was established.

In conclusion, both Genistein and Daidzein are safe, effective, and eco-friendly chemicals and isoflavones displayed potential nematicidal against $H$. glycines. The inhibition of the isoflavones to J2 motility, respiration, and body fluid depended on dosage and exposure time. Further studies on mechanisms is required to maximize the control application against SCN.

\section{Acknowledgments}

This work was supported by the National Nature Science Fund Key Projects (313300630), the Special Fund for China Agriculture Research System (CARS-04-PS13) and National Parasitic Resources Center (NPRC-2019194-30).

\section{Authors' Contributions}

Conceptualization: Duan, Y.X.; Zhu, X.F. Data acquisition: $\mathrm{Ma}$, Y.Z.; Yuan, R.H. Data analysis: Ma, Y.Z.; Yuan, R.H.; Sikandar, A. Design of methodology: Ma, Y.Z.; Wang, Y.Y. Writing and editing: Sikandar, A.; Wang, Y.Y.

\section{References}

Anjam, M.S.; Shah, S.J.; Matera, C.; Różańska, E.; Sobczak, M.; Siddique, S.; Grundler, F.M. 2020. Host factors influence the sex of nematodes parasitizing roots of Arabidopsis thaliana. Plant, Cell and Environment 43: 1160-1174.

Basyoni, M.M.; Rizk, E.M. 2016. Nematodes ultrastructure: complex systems and processes. Journal of Parasitic Diseases 40: 1130-1140.

Bell, C.A.; Lilley, C.J.; McCarthy, J.; Atkinson, H.J.; Urwin, P. 2019. Plant-parasitic nematodes respond to root exudate signals with host-specific gene expression patterns. PLoS Pathogens 15: e1007503.

Blaxter, M.; Denver, D.R. 2012. The worm in the world and the world in the worm. BMC Biology 10: 57.

Cesco, S.; Mimmo, T.; Tonon, G.; Tomasi, N.; Pinton, R.; Terzano, R.; Neumann, G.; Weisskopf, L.; Renella, G.; Landi, L. 2012. Plant-borne flavonoids released into the rhizosphere: impact on soil bio-activities related to plant nutrition: a review. Biology and Fertility of Soils 48: 123-149.

Chin, S.; Behm, C.A.; Mathesius, U. 2018. Functions of flavonoids in plant-nematode interactions. Plants 7: 85 .

Croll, N.A. 1975. Behavioural analysis of nematode movement. Advances in Parasitology 13: 71-122.

Duan, Y.; Chen, L.; Liu, G.; Li, H.; Wang, X.; Wang, Y. 2011. Plant Pathogenic Nematodes: The Economic Importance of Plant Pathogenic Nematodes. Sinece Press, Beijing, China.

Faizi, S.; Fayyaz, S.; Bano, S.; Yawar Iqbal, E.; Siddiqi, H.; Naz, A. 2011. Isolation of nematicidal compounds from Tagetes patula L. yellow flowers: structure-activity relationship studies against cyst nematode $H$. zeae infective stage larvae. Journal of Agricultural and Food Chemistry 59: 9080-9093.

Fanelli, E.; Troccoli, A.; Picardi, E.; Pousis, C.; De Luca, F. 2014. Molecular characterization and functional analysis of four $\beta$-1, 4-endoglucanases from the root-lesion nematode Pratylenchus vulnus. Plant Pathology 63: 1436-1445.

Grundler, F.; Schnibbe, L.; Wyss, U. 1991. In vitro studies on the behaviour of second-stage juveniles of Heterodera schachtii (Nematoda: Heteroderidae) in response to host plant root exudates. Parasitology 103: 149-155.

Guo, C.; Zhu, X.; Duan, Y.; Wang, Y.; Chen, L. 2017. Suppression of different soybean isoflavones on Heterodera glycines. Chinese Journal of Oil Crop Sciences 39: 540-545.

Hernando, G.; Turani, O.; Bouzat, C. 2019. Caenorhabditis elegans muscle Cys-loop receptors as novel targets of terpenoids with potential anthelmintic activity. PLoS Neglected Tropical Diseases 13: e0007895.

Hosseini, P.; Matthews, B.F. 2014. Regulatory interplay between soybean root and soybean cyst nematode during a resistant and susceptible reaction. BMC Plant Biology 14: 300.

Hussey, R. 1985. Staining Nematodes in Plant Tissue: Plant Nematology Laboratory Manual. University of Massachusetts Agricultural Experimental Station, Amherst, MA, USA.

Jones, T.B. 2005. Electromechanics of Particles. Cambridge University Press, New York, NY, USA. 
Kar, P.; Tandon, V. 2000. Anthelmintic efficacy of Flemingia vestita (Fabaceae): genistein induced effect on the nervous components in two digenetic trematodes. Journal of Parasitic Diseases 24: 141-146.

Kohno, Y.; Watanabe, M.; Hosokawa, D. 1981. Studies on the Physiological changes in the rice plants infected with Xanthomonas campestris pv. oryzae. Japanese Journal of Phytopathology 47: 555-561.

Kohra, S.; Tominaga, N.; Takao, Y.; Nagae, M.; Ishibashi, Y.; Ueda, K.; Arizono, K. 2002. A rapid respiratory toxicity test using Caenorhabditis elegans with an oxygen electrode system. Journal of Health Science 48: 269-272.

Lai, Y.; Liu, K.; Zhang, X.; Zhang, X.; Li, K.; Wang, N.; Shu, C.; Wu, Y.; Wang, C.; Bushley, K.E. 2014. Comparative genomics and transcriptomics analyses reveal divergent lifestyle features of nematode endoparasitic fungus Hirsutella minnesotensis. Genome Biology and Evolution 6: 3077-3093.

Lambert, K.; Bekal, S. 2002. Introduction to plant-parasitic nematodes. The Plant Health Instructor 10: 1094-1218.

Lee, Y. -U.; Kawasaki, I.; Lim, Y.; Oh, W. -S.; Paik, Y. -K.; Shim, Y. -H. 2008. Inhibition of developmental processes by flavone in Caenorhabditis elegans and its application to the pinewood nematode, Bursaphelenchus xylophilus. Molecules and Cells 26: 171-174.

Liu, W. 1995. The Research Technique of Plant Pathogenic Nematodes: Screen Method of Nematodes in Soil and Plants. Liaoning Science and Technology Press, Shenyang, China.

Luo, H.; Liu, Y.; Fang, L.; Li, X.; Tang, N.; Zhang, K. 2007. Coprinus comatus damages nematode cuticles mechanically with spiny balls and produces potent toxins to immobilize nematodes. Applied and Environmental Microbiology 73: 3916-3923.

Maule, A.; Halton, D.; Shaw, C.; Johnston, C. 1993. The cholinergic, serotoninergic and peptidergic components of the nervous system of Moniezia expansa (Cestoda, Cyclophyllidea). Parasitology 106: 429-440.

Muller, J.; Rehbock, K.; Wyss, U. 1981. Growth of Heterodera schachtii with remarks on amounts of food consumed. Revue de Nematologie 4: 227-234.

Page, A.P.; Stepek, G.; Winter, A.D.; Pertab, D. 2014. Enzymology of the nematode cuticle: a potential drug target? International Journal for Parasitology: Drugs and Drug Resistance 4: 133141.

Pal, P.; Tandon, V. 1998. Anthelmintic efficacy of Flemingia vestita (Fabaceae): genistein-induced alterations in the esterase activity in the cestode, Raillietina echinobothrida. Journal of Biosciences 23: 25-31.

Pierce-Shimomura, J.T.; Morse, T.M.; Lockery, S.R. 1999. The fundamental role of pirouettes in Caenorhabditis elegans chemotaxis. Journal of Neuroscience 19: 9557-9569.

Preez, G.D.; Fourie, H.; Daneel, M.; Miller, H.; Höss, S.; Ricci, C.; Engelbrecht, G.; Zouhar, M.; Wepener, V. 2020. Oxygen consumption rate of Caenorhabditis elegans as a highthroughput endpoint of toxicity testing using the Seahorse XF e 96 Extracellular Flux Analyzer. Scientific Reports 10: 1-11.

Qi, Z.; Chen, C.; Wang, J.; Zhou, M. 2008. Mode of action of methylene bisthiocyanate and its decomposition products to Meloidogyne spp. juveniles. Acta Phytopathologica Sinica 38: 420-424.
Schafer, W. 2016. Nematode nervous systems. Current Biology 26: R955-R959.

Schouest, K.; Zitova, A.; Spillane, C.; Papkovsky, D.B. 2009. Toxicological assessment of chemicals using Caenorhabditis elegans and optical oxygen respirometry. Environmental Toxicology and Chemistry 28: 791-799.

Shaukat, S.S.; Siddiqui, I.A.; Ali, N.I.; Ali, S.A.; Khan, G.H. 2003. Nematicidal and allelopathic responses of Lantana camara root extract. Phytopathologia Mediterranea 42: 71-78.

Sikandar, A.; Zhang, M.Y.; Zhu, X.F.; Wang, Y.Y.; Ahmed, M.; Iqbal, M.F.; Javeed, A.; Xuan, Y.H.; Fan, H.Y.; Liu, X.Y.; Chen, L.J.; Duan, Y.X. 2019. Effects of Penicillium chrysogenum strain Snef1216 against root-knot nematodes (Meloidogyne incognita) in cucumber (Cucumis sativus L.) under greenhouse conditions. Applied Ecology and Environmental Research 17: 12451-12464.

Sommerville, R.; Davey, K. 2002. Diapause in parasitic nematodes: a review. Canadian Journal of Zoology 80: 1817-1840.

Son, S. -H.; Khan, Z.; Moon, H.S.; Kim, S.G.; Moon, Y.; Choi, D. -R.; Kim, Y.H. 2007. Nematicidal activity of secondary metabolites of a plant growth promoting rhizobacterium, Paenibacillus polymyxa. Russian Journal of Nematology 15: 95-100.

Tandon, V.; Das, B. 2018. Genistein: is the multifarious botanical a natural anthelmintic too? Journal of Parasitic Diseases 42: 151161.

Tandon, V.; Lyndem, L. 2010. Anthelmintic efficacy of medicinal palnts from Northeast India against hookworms: an in vitro study on Ancylostoma Ceylanicum. Pharmacologyonline 3: 697-707.

Toner, E.; McConvery, F.; Brennan, G.; Meaney, M.; Fairweather, I. 2009. A scanning electron microscope study on the route of entry of triclabendazole into the liver fluke, Fasciola hepatica. Parasitology 136: 523-535.

Tsalik, E.L.; Hobert, O. 2003. Functional mapping of neurons that control locomotory behavior in Caenorhabditis elegans. Journal of Neurobiology 56: 178-197.

Vafai, S.B.; Mootha, V.K. 2012. Mitochondrial disorders as windows into an ancient organelle. Nature 491: 374-383.

Vieira, P.; Eves-Van Den Akker, S.; Verma, R.; Wantoch, S.; Eisenback, J.D.; Kamo, K. 2015. The Pratylenchus penetrans transcriptome as a source for the development of alternative control strategies: mining for putative genes involved in parasitism and evaluation of in planta RNAi. PloS One 10: e0144674.

Warnock, N.D.; Wilson, L.; Canet-Perez, J.V.; Fleming, T.; Fleming, C.C.; Maule, A.G.; Dalzell, J.J. 2016. Exogenous RNA interference exposes contrasting roles for sugar exudation in host-finding by plant pathogens. International Journal for Parasitology 46: 473-477.

Wuyts, N.; Swennen, R.; De Waele, D. 2006. Effects of plant phenylpropanoid pathway products and selected terpenoids and alkaloids on the behaviour of the plant-parasitic nematodes Radopholus similis, Pratylenchus penetrans and Meloidogyne incognita. Nematology 8: 89-101.

Yeates, G.W.; Bongers, T.D.; De Goede, R.G.M.; Freckman, D.W.; Georgieva, S.S. 1993. Feeding habits in soil nematode families and genera: an outline for soil ecologists. Journal of Nematology 25: 315-331.

Zhao, W. -x.; Sun, Z. -q.; Gao, Y. -h.; Zhang, N. 2007. Studies on the extraction technological conditions of total flavonoids in soybean hull and its nematicidal activity. Soybean Science 26: 373-376. 